\title{
LA CONSTRUCCIÓN DE LA REGIÓN EN LA HISTORIOGRAFÍA CHAQUEÑA DEL SIGLO XX. LA PERSPECTIVA DE GUIDO MIRANDA
}

\section{María Silvia Leoni}

La cuestión de la definición regional de lo que hoy se denomina Nordeste argentino ha estado sometida a miradas contrapuestas. Las diversas concepciones en torno a la región condujeron a delinear límites distintos y a buscar sus raíces históricas en diferentes momentos y circunstancias ${ }^{1}$. En este caso, la dificultad para definir el ámbito regional se ha manifestado, entre otras, en la ausencia de "historias regionales". Es por ello que nos interesa analizar las propuestas de un autor cuya obra ha sido central en la historiografía chaqueña y que sólo recientemente ha merecido estudio² ${ }^{2}$ Guido Miranda (1912-1994), maestro y periodista incorporado a las filas del socialismo, es autor de una obra considerada un clásico: Tres ciclos chaqueños (Crónica histórica regional) (1955); a través de su producción escrita, buscó desentrañar la identidad regional.

En este trabajo nos proponemos interrogar al ensayo de Miranda más que como clave de interpretación, como fuente compleja de representaciones de la región ${ }^{3}$, partiendo de la hipótesis de que cumple un papel fundamental en su construcción la recepción de la obra de Bernardo Canal Feijóo, con quien Miranda establece un continuo diálogo para su elaboración de una propuesta de historia regional.

\section{La construcción de una historia para el Chaco}

La preocupación por la historia de la zona chaqueña ha sido escasa en el ámbito nacional. Los primeros aportes al conocimiento geohistórico de la región se debieron a los religiosos que se introdujeron para evangelizar a los indígenas y a los exploradores que cruzaron el territorio en busca de rutas alternativas para conectar el noroeste con el litoral fluvial.

Las visiones referentes al Chaco elaboradas en la segunda mitad del siglo XIX provienen de los discursos de los representantes del gobierno nacional y de quienes

\footnotetext{
${ }^{1}$ Así como se han producido debates en torno a la construcción de las naciones, los ha habido con respecto a las regiones, en los cuales se han enfrentado posiciones constructivistas frente a otras esencialistas.

${ }^{2}$ Una completa exposición de su biografía y un análisis de su producción en dos trabajos de Delia Teresita Álvarez de Tomassone: Guido Miranda, testigo e intérprete del pasado chaqueño. Resistencia, ed. del autor, 2004 y Guido Miranda. Enhebrando los recuerdos de su vida. Resistencia, Subsecretaría de Cultura de la Provincia del Chaco, 2001.

${ }^{3}$ Seguimos aquí a Adrián Gorelik. "Mapas de identidad. La imaginación territorial en el ensayo de interpretación nacional: de Ezequiel Martínez Estrada a Bernardo Canal Feijóo”. En: Prismas, UNQ, No5, 2001.
} 
pertenecían a instituciones vinculadas con el mismo, como el Instituto Geográfico Argentino y la Sociedad Geográfica Argentina, integradas por funcionarios, militares y aficionados involucrados en las prácticas de apropiación material del Chaco. Estas sociedades publicaron revistas y boletines, en los cuales los relatos de expediciones y campañas al Chaco fueron uno de los tópicos recurrentes y más extensamente abordados. Sus trabajos sostenían la imagen del Chaco como un "desierto verde", un vasto espacio sin historia, dotado de existencia a partir de los descubrimientos de las empresas exploradoras. La historia tenía su punto de arranque en el entonces reciente proceso de ocupación por parte del estado nacional. El Chaco parecía no tener un pasado; sólo un presente y un futuro. Al ser un área "vacía", le correspondió a la geografía volverla objeto de conocimiento y ocupar así un lugar privilegiado en la formación de una conciencia territorial nacional ${ }^{5}$.

Finalizada la conquista e iniciado exitosamente el proceso de incorporación al sistema nacional dentro del modelo de economía primaria exportadora, a través de la explotación del quebracho primero y del cultivo del algodón después, surgió la necesidad de brindar una imagen del Chaco que demostrara los avances logrados por sus nuevos habitantes en tan poco tiempo. Se comenzó a sentir la necesidad de disponer de alguna forma de saber organizado en torno a los orígenes, las características y el sentido del desarrollo chaqueño, sus rasgos distintivos, sus logros y fracasos. Ese comienzo de reflexión histórica se produjo cuando entró en debate el modelo político y social por construir y los modos de resolver las cuestiones propias de una sociedad organizada ${ }^{6}$.

Las características del poblamiento del Chaco determinaron la heterogeneidad y movilidad de su sociedad ${ }^{7}$. No hubo una elite con fuerte tradición histórica; el proceso de elitización se produjo fundamentalmente a través del éxito económico: los inmigrantes exitosos se sumaron a integrantes de la elite correntina con vínculos en el territorio, profesionales y altos funcionarios públicos llegados con cada nueva gestión, representantes de las grandes empresas radicadas en el Chaco y a un reducido grupo intelectual, conformado por los dueños de periódicos, directores de escuelas y algunos profesores de los escasos colegios secundarios existentes. Esta elite se relacionó a través de agrupaciones étnicas, la Sociedad Rural, la Cámara de Comercio y otras instituciones sociales, culturales y recreativas que fueron surgiendo en las primeras décadas del siglo XX. Esta elite sería la encargada de "pensar el Chaco" y de ofrecer una imagen positiva de su pasado, presente y futuro para insertarlo en el proceso histórico nacional.

\footnotetext{
${ }^{4}$ Carla Mariana Lois y Claudia Alejandra Troncoso. "Integración y desintegración indígena en el Chaco: los debates en la Sociedad Geográfica Argentina (1881-1890)". En: $1^{\circ}$ Congreso Virtual de Antropología y Arqueología, octubre de 1998. URL: www.naya.org.ar.

5 Beatriz Dávilo y Claudia Gotta (comp) Narrativas del desierto, geografías de la alteridad". Rosario, UNR, 2000, pp. 61-74.

${ }^{6}$ Néstor Tomás Auza. “La cultura histórica”. En: Academia Nacional de la Historia. La Junta de Historia y Numismática Americana y el movimiento historiográfico en la Argentina. Buenos Aires, ANH, 1996. t.II, p. 404.

${ }^{7}$ Para mediados del siglo XX, más del $90 \%$ de los habitantes del Chaco eran argentinos, pero sólo un 56\% había nacido en la jurisdicción. Estas cifras indican que, ya para entonces, la calidad de "tierra de inmigrantes" era más una consecuencia de la convergencia hacia el Chaco de migrantes de provincias argentinas que de europeos, aunque la imagen de "crisol de razas" perduraría a través del tiempo.
} 
En el período territoriano no podemos hablar en el Chaco de la constitución de un campo historiográfico, sino de la existencia de un protoespacio historiográfico ${ }^{8}$. No existía el historiador profesional ni instituciones que favorecieran este desarrollo, y quienes se volcaron a la historia, en muchos casos ocasionalmente (periodistas, docentes, naturalistas, sacerdotes), la consideraron una tarea complementaria de sus otras actividades. Por otro lado, los principales historiadores correntinos, Manuel F. Mantilla y Hernán F. Gómez, abordaron el pasado chaqueño en tanto se vinculaba con la historia de su propia provincia.

A partir de la década de 1930, en un contexto historiográfico nacional favorable, apareció reiteradamente la alusión al papel del ejército argentino en los orígenes de la historia chaqueña. Se resaltaba fundamentalmente la gesta que había permitido la incorporación efectiva del territorio a la nación, tras terminar con la oposición indígena, abriéndolo para la inmigración y el consecuente progreso material, que entonces se avizoraba como ininterrumpido. Se destacaba también la "argentinidad" de los habitantes y el esfuerzo de estos argentinos por civilizar territorios ganados al desierto y al indígena.

Por otro lado, la Iglesia católica se había insertado en el espacio chaqueño desde mediados de la década de 1930, con la creación de la Vicaría Eclesiástica para Chaco y Formosa. A cargo de ella quedó Monseñor Nicolás De Carlo, luego primer Obispo de la diócesis de Resistencia (1940-1951), quien imprimió gran dinamismo a las actividades de la Iglesia, acompañado por el presbítero José Alumni9. En la década de 1940, en el marco de un nacionalismo hispanófilo y católico, se advierte el esfuerzo por rescatar las raíces católicas e hispánicas de la cultura chaqueña. Los trabajos arqueológicos, la producción historiográfica y la conmemoración, en 1950, del bicentenario de la fundación de la reducción de San Fernando del Río Negro, son algunos de los indicadores.

La relación de la sociedad con su pasado cumplió un importante papel en la conformación de la identidad territoriana. Inicialmente, el interés se centró en los orígenes de las ciudades y pueblos, lo que permitió dar una filiación a determinados grupos para que jerarquizaran su ubicación en la estructura social. En el caso de la ciudad de Resistencia, este aspecto se observa en la discrepancia en torno a sus "verdaderos" fundadores.

En este sentido, fue exitosa la perspectiva que tomaba como hito inicial del proceso histórico la colonización de Resistencia, producto de la inmigración, y que desconocía la historicidad de las etapas anteriores, en un esfuerzo por demostrar el carácter original del desarrollo chaqueño y marcar su autonomía con respecto a la tutela política y cultural de Corrientes. A partir del 2 de febrero de 1878, el Chaco había progresado gracias al tesón y el sacrificio del inmigrante.

El periodismo reconoció el lugar de la historia en la construcción de una identidad chaqueña y cumplió un papel central en el despertar de una conciencia histórica, tanto a

\footnotetext{
8 Tomamos la noción de Gustavo Prado "Las condiciones de existencia de la historiografía decimonónica argentina". En: Fernando Devoto y otros. Estudios de Historiografía argentina (II). Buenos Aires, Biblos, 1999.

9 Para este tema véase Helga Nilda Goicoechea. La diócesis de Resistencia. Un obispado de frontera (1878-1957). Corrientes, Eudene, 1998.
} 
través de la publicación de artículos sobre temas históricos, como del incentivo dado a las investigaciones y a los actos conmemorativos.

Si bien la producción historiográfica chaqueña tuvo un escaso desarrollo hasta mediados de siglo, asistimos para entonces a un incremento de esta actividad con la labor de quienes serían figuras destacadas en este campo.

Los historiadores, sin inserción institucional, fueron actores aislados, como Enrique Lynch Arribálzaga -quien buscó establecer sin éxito una institución en el ámbito municipalJuan Ramón Lestani y Alumni; no obstante, este último contó con el respaldo de la Iglesia y del gobierno chaqueño bajo el peronismo.

Aunque desde distintas perspectivas, buscaron en el pasado las líneas de acción que llegaban a su presente, en un intento por rescatar los elementos que consideraban valiosos para orientar a esa nueva sociedad en gestación: Lynch Arribálzaga el legado criollo, Alumni las raíces católicas, Lestani el aporte de los inmigrantes europeos. A ellos se sumaría el entonces prestigioso historiador correntino Hernán Gómez, quien buscó demostrar el aporte de sus comprovincianos en la construcción de la historia chaqueña. Todos ellos contribuyeron a legitimar las imágenes del Chaco que buscaban imponerse en la memoria colectiva.

En este contexto intelectual se insertará la producción de Guido Miranda.

\section{Breve itinerario del autor y su obra}

Guido Miranda (1912-1994) nació en Vera (Santa Fe) y falleció en Resistencia. Se recibió de maestro en la Escuela Normal de esta última ciudad en 1930, para luego desempeñarse como docente en escuelas del interior chaqueño. Integró la redacción de distintos periódicos y dirigió la revista Región. Se incorporó a las filas del socialismo a fines de la década de 1940.

$\mathrm{Su}$ labor historiográfica comenzó en las postrimerías del gobierno peronista y su primera contribución se produjo en el marco de la impugnación a la constitución provincial de 1951. Esta impugnación a lo actuado por el peronismo tuvo su expresión simbólica en el reclamo de restitución de su primitivo nombre a la provincia, que había pasado a denominarse Presidente Perón, y en la defensa de una tradición histórica marcada por el laicismo y el aporte inmigratorio.

Edgardo Rossi, otra destacada figura del socialismo chaqueño, realizó la reivindicación histórica y cultural del nombre "Chaco" con la colaboración de Miranda, reivindicación que encerraba la total oposición de los sectores antiperonistas frente a las transformaciones ocurridas en la provincia, al sostener que la denominación "Chaco" "tiene en nuestro pueblo presencia anímica y corporal permanente, residencia histórica y cultural definitiva" para luego insistir en que "se consubstancia y confunde con el ser y el sentir de este pueblo, que no reconoce otra denominación para identificar los valores esenciales de su tradición, ni sabe de otro título para sentirse incorporado al seno de la comunidad argentina sin desmedro de su personalidad, que el de ser "Chaqueño"10. Como se verá,

${ }^{10}$ Edgardo Rossi. Reivindicación del Chaco; En defensa de la República. La Plata, Parlamento Libre, 1952, p.44. 
esta reivindicación del término respondía a una concepción de la región a la que adhería Miranda.

En este contexto de enfrentamiento peronismo/antiperonismo, Miranda publicó en 1954 El paisaje chaqueño, presentada como un "ensayo de geografía regional", obra que estudia el medio geográfico, al determinar su importancia “para la interpretación de múltiples aspectos del desarrollo histórico y social”. Desde una perspectiva muy arraigada, incluyó a los pueblos aborígenes, que son presentados como expresión de este medio, ahistóricos y escasamente determinantes en la conformación de la identidad chaqueña; aunque al igual que Juan Ramón Lestani, revela una mirada apesadumbrada ante la consideración de un trágico destino que parecía ineluctable.

Al año siguiente apareció la obra que se transformaría en un clásico de la historiografía provincial: Tres ciclos chaqueños (Crónica histórica regional). En ella, parte de la fundación de Resistencia para llegar a 1950, a través de "un cuadro somero del proceso de ocupación del territorio, que con cierta vocación de equidad pretende abarcar todas las fases constructivas de la aventura colonizadora"11. Siguiendo una interpretación ya establecida, la historia se inicia con el proceso de ocupación del espacio a fines del siglo XIX y, más específicamente, con el surgimiento de la colonia Resistencia.

El autor catalogó a este libro como "la respuesta de la ciudadanía libre a la Convención Constituyente de 1951", en referencia a la labor que culminó con la sanción de la Constitución de ese año -a la cual el socialismo denunció como corporativista y fascistay se sintió "vocero de una corriente de opinión que latía por debajo de la uniformidad rasante que las autoridades imponían sobre la expresión de las ideas"12. Allí está presente, no obstante, una visión del desarrollo histórico chaqueño ya generalizada que destaca el aporte de los pioneros y lo proyecta esperanzadoramente hacia el futuro, como se refuerza en el último párrafo de la obra:

¿De qué carencia padecerá nuestro ánimo, que no seamos capaces de concebir, con la fe de estas generaciones cuyo esfuerzo mancomún hemos evocado, los motivos de nuevas obras de aliento creador, para revalidar el espíritu de empresa que ha tenido la colonización chaqueña? ${ }^{13}$

Producida la llamada "Revolución Libertadora", Miranda fue designado secretario de la Convención Constituyente de 1957. Los debates en torno a la nueva Constitución revelan la búsqueda de las raíces históricas para fundar las propuestas realizadas. Junto con su proyecto de Constitución, los convencionales socialistas habían presentado a la Convención Provincial una Exposición de Motivos, en la cual acudían al pasado chaqueño para fundamentar la Constitución proyectada. Se proponía allí que "una auténtica Constitución debe partir del estudio ordenado de la realidad geográfica, histórica, cultural,

${ }^{11}$ Guido Miranda. Tres ciclos chaqueños (Crónica histórica regional). Santa Fe, Norte Argentino, 1955, p. 283.

12 Ibid. Nota final a la edición 1980.

${ }^{13}$ Ibid, p. 312. 
económica y social del Chaco. Para ser tal, nuestra Constitución tiene que recoger los rasgos esenciales de la estructura provincial" ${ }^{14}$. Al referirse a las circunstancias históricas, afirmaba que

"Ha sido común que hasta el presente se enumerasen en forma cronológica los distintos intentos de conquistas, sin analizar las instituciones que en cada caso fueron elegidas como instrumento de penetración. Vamos a poner de manifiesto, creemos que por primera vez, una interpretación fundada en hechos históricos del Chaco que revelará consecuencias de marcado tono sociológico, aprovechables para una correcta ubicación de nuestra sociedad"15

Las instituciones consideradas, con los respectivos resultados obtenidos, según esta perspectiva, fueron el sistema de encomiendas, que fracasó; el sistema de la reducción, que constituía un sistema cerrado, sin salida al porvenir y que también fracasó y el ensayo de la colonia agrícola, con la Ley No 817 de 1876, que obtuvo excelentes resultados: "El Chaco es, si se trata de aprehender en un concepto el milagro tentacular de su prosperidad actual, el crecimiento cuantitativo y cualitativo de la colonia agrícola que elaboraron como célula civilizadora los gobernantes argentinos, entre 1853 y 1880 ”. De esta última comprobación, los convencionales socialistas extraerían la premisa subyacente al Artículo $1^{\mathrm{o}}$ de la Constitución, el cual puntualiza cuáles deben ser los aspectos tipificantes de la organización política chaqueña: "un Estado fundado en el trabajo, que organiza su gobierno bajo el sistema republicano, democrático, social y laico".

Esta mirada ampliamente favorable de la labor de la generación del 80 y del proceso de modernización que incluyó al Chaco, es un rasgo distintivo con respecto a las posturas de reivindicación regional surgidas en otros espacios, como por ejemplo Santiago del Estero con Bernardo Canal Feijóo, como veremos.

Miranda se alineó con el Partido Socialista Democrático y fue candidato a vicegobernador en 1962 y a gobernador en 1973.

Por otro lado, ha sido el primer historiador que ha indagado en el campo cultural, a través de dos obras: Al norte del paralelo $28^{\circ}$ (1966) y Fulgor del desierto verde (1925-1947) (1985), con las cuales buscó completar la tercera parte de la trilogía proyectada, que contemplaba el paisaje, el desarrollo socioeconómico y la vida cultural. Analiza el movimiento intelectual que denomina "generación del 37" y define como el "núcleo informal de neoinmigrantes que sentaron reales en el descampado cultural de Resistencia durante los años 1933-1938"16. En estos trabajos, que le permiten establecer su filiación intelectual, presenta en forma asistemática figuras, obras e instituciones que marcaron el desarrollo cultural del Chaco, a través de información proporcionada por periódicos o el propio recuerdo del autor, a lo cual se le agregan algunos interesantes intentos explicativos.

\footnotetext{
14 "Constitución política y circunstancias históricas. Una exposición de motivos". En: Resistencia, Resistencia, año II, No $59,17-X I-1957$, p.1.

${ }^{15}$ Ibid

${ }^{16}$ Guido Miranda. Fulgor del desierto verde (1925-1947) Resistencia, Región, 1985, p. 19.
} 
Creada la Universidad Nacional del Nordeste (1957), trabajó en el Departamento de Extensión Universitaria. En 1982, dicha Universidad le otorgó el Doctorado Honoris Causa, fundamentado en su original interpretación de los ciclos históricos de la región, su función en la docencia primaria y universitaria, sus informes y proyectos destinados a elevar la calidad de la enseñanza, establecer orientaciones didácticas y ampliar fuentes documentales, su labor periodística y por forjar las raíces de los estudios humanísticos en la región y en el país. Se manifestaba así el reconocimiento por parte de la Universidad hacia quienes, sin haber recibido una formación académica, habían ocupado un lugar central en el campo intelectual chaqueño, en un acercamiento ante la dicotomía planteada entre universitarios y no universitarios.

\section{Lecturas y recepciones}

Con anterioridad a la obra de Miranda, encontramos un intento por dotar a los chaqueños de una obra de historia local general. El ya mencionado Hernán Gómez en su Historia de la Gobernación del Chaco (1939) señalaba la importancia del conocimiento del pasado para que "los futuros ciudadanos de estas zonas... se sitúen en la armonía indivisa del espíritu nacional y rehagan los viejos enlaces que estructuraron la patria". En su obra destacaba una historia de siglos, en la cual "es siempre mayoría la estirpe de la provincia limítrofe de Corrientes, cuya emigración forma el protoplasma fecundo de tanta maravilla"17. Como lo indica este párrafo, la perspectiva que en la obra impera está orientada a remarcar el papel de Corrientes en el desarrollo del Chaco, en un proceso en el cual el arribo de los inmigrantes cumple un papel secundario.

Pero la producción regional que más impactó en Miranda fue la de Juan Ramón Lestani ${ }^{18}$. Precisamente, Miranda se inserta en la incipiente tradición historiográfica del socialismo local, encarnada en el citado Lestani y en Eduardo Miranda Gallino. El primero encaró el análisis del pasado reciente en El Territorio Nacional del Chaco (Oro y miseria) (1935), para señalar los problemas subyacentes al progreso económico y abogar por la ampliación de la participación política de los habitantes. El subtítulo Oro y miseria resume en una frase la visión que Lestani tenía del Chaco: tras el brillo del desarrollo económico, el sufrimiento de quienes no gozaban de sus beneficios. La obra pretendía ser "un alegato hiriente en defensa de nuestros derechos de ciudadanos argentinos"19.

\footnotetext{
${ }^{17}$ Hernán F. Gómez Historia de la Gobernación Nacional del Chaco. Buenos Aires, s/e, 1939; p. 8.

18 Juan R. Lestani había nacido en Resistencia en 1904; pertenecía a la tercera generación de una de las familias italianas que desembarcaron en 1878 para poblar la nueva colonia y cuyos descendientes formaron parte de la elite local. Destacado político socialista, fue el primer intendente nativo de Resistencia (1933-1935 y 19401942). Se dedicó al periodismo político y participó en la gestación de varios movimientos por los derechos políticos de los territorianos. Representó al Chaco en distintos congresos de Territorios, municipales, algodoneros y de escritores. Publicó diversos trabajos referidos a la realidad chaqueña y a sus observaciones como viajero por Europa. Véase nuestro trabajo "Una perspectiva sobre la construcción del ciudadano en el territorio nacional del Chaco. Diagnóstico y propuestas de Juan Ramón Lestani”. En: Pilquen - Sección Ciencias Sociales, № 7, 2005/2006. URL: www.revistapilquen.com.ar/

19 J.R. Lestani, El Territorio Nacional del Chaco Geográfico-político-económico y social (Oro y miseria) Resistencia, s/e, 1935, p. 3.
} 
En Unidad y conciencia (1938) Lestani persigue el objetivo de dar contenido moral a una sociedad pragmática, para lo cual analiza las características del ambiente, pues "las condiciones de vida de nuestro medio han creado una modalidad especial en el carácter de nuestros hombres", modalidad que se manifiesta en el imperio del advenedizo y el espíritu de oportunidad y servilismo. Para realizar su diagnóstico, recurre a la historia de Resistencia, a partir de 1878, que le permite explicar la conformación moral de sus actuales habitantes.

Miranda retomaría las preocupaciones de Lestani: buscó desentrañar la identidad histórica y cultural del Chaco, para lo cual proporcionó una visión globalizadora del desarrollo histórico chaqueño y otorgó centralidad a los procesos socio-económicos. Su reconocimiento a la contribución de Lestani se manifiesta en unos breves trabajos que le dedicara a este autor ${ }^{20}$.

Por otro lado, el mismo Miranda ha señalado la importancia en su formación autodidacta de las lecturas de Waldo Frank y André Malraux y, entre los escritores e intelectuales argentinos, ensayistas como Ezequiel Martínez Estrada ${ }^{21}$, Carlos Alberto Erro, Eduardo Mallea, Francisco Romero y Bernardo Canal Feijóo ${ }^{22}$. Consideramos que esta última recepción tuvo una fuerte impronta en la configuración de su interpretación de la historia regional ${ }^{23}$.

Dentro del ensayismo se advierte una "larga tradición argentina que identifica en el territorio la clave de los males del país, que en la palabra desierto equipara ausencia de naturaleza y ausencia de pasado... ausencia de cultura" ${ }^{24}$. Hay una fuerte matriz espacial en las explicaciones sobre la sociedad y la cultura argentina, con la metaforización del mapa como cuerpo de la nación y el descubrimiento de que el hombre y la cultura son telúricos.

${ }^{20}$ Véase "Personalidad de Juan R. Lestani". En: Boletín del Fogón de los Arrieros, Resistencia, año V, No 59, 1957 y “Juan R. Lestani. Una senda de papel en la espesura semivirgen del bosque chaqueño". En: Norte, Resistencia, 26-XI-1978. También los apartados que le dedica en Fulgor del desierto verde y Al norte del paralelo 28 .

${ }^{21}$ A un mes del fallecimiento de Martínez Estrada publicó un artículo "Ezequiel Martínez Estrada, escritor e ideólogo". En: Nordeste, Facultad de Humanidades, UNNE, Nº, 1964. Y más adelante, "La indagación del ser argentino. Ezequiel Martínez Estrada”. En: Norte, Resistencia, 19-X-1978.

22 Delia Teresita Álvarez de Tomassone. "Las corrientes historiográficas y la primera historiografía chaqueña: El caso Guido Miranda. En: Interpretaciones. Revista de Historiografía Argentina, No 2, primer semestre de 2007. URL: www.historiografia-arg.org.ar/

23 Bernardo Canal Feijóo, nació en Santiago del Estero en 1897 y falleció en Bs. As. en 1982. Abogado, ensayista y dramaturgo, fue autor de obras sustantivas en la indagación de la realidad nacional. Fue fundador del grupo cultural "La Brasa” (1925-1947), que reunió a los más nombrados intelectuales santiagueños de la época, organizador del IPINOA (Instituto de Planificación Integral del Noroeste Argentino), integrante de la Revista Sur, decano de la Facultad de Humanidades de la Universidad Nacional de la Plata, secretario de Cultura de la Universidad de Bs. As. y presidente de la Academia Argentina de Letras. Véase Beatriz Ocampo. "Un ritual secular y "la invención de la tradición" en Santiago del Estero". En: V Congreso de Antropologia Social, La Plata, NAyA, Julio-Agosto 1997. URL: www.naya.org.ar/miembros/congresos/ contenido/laplata/LP4/22.htm

24 Ibid. 
Canal Feijóo es uno de los pensadores más importantes del Noroeste argentino $\mathrm{y}$ autor de numerosos trabajos en los que se ha estimado que convergen la visión del historiador, el examen político institucional, la interrogación sociológica, la descripción monográfica y la percepción literaria ${ }^{25}$, característica que también se ha atribuido a la obra de Miranda. En los años '30 y '40 Canal orientó parte de su producción hacia el ensayo con Proposiciones en torno del problema de una cultura nacional (1944) y De la estructura mediterránea argentina (1948). En estas obras habría propuesto una inversión casi copernicana de los términos centro-periferia: el centro fundante estaría en la provincia y sería una deformación asignar un rol hegemónico a Buenos Aires. Esta relación centro-periferia también está presente en la obra de Miranda, pero de una forma no conflictiva, como analizaremos más adelante. Canal y Miranda presentan la similar necesidad de encarnar sus figuraciones de identidad en metáforas territoriales; ambos son cosmopolitas y modernos. Canal, según Beatriz Ocampo, pensaba la heterogeneidad de los interiores del país, el espacio ocupado, que tiene un pasado y un presente y que puede proponer otro modo de demarcación del espacio para la nación argentina, distinto al proyecto civilizador de la generación del 80 . En este último punto, Miranda se alejaría de aquella clave interpretativa.

Debe tenerse en cuenta que el contexto de producción de Canal era diferente al de Miranda: la década del 40 corresponde a los años que marcan a Santiago del Estero con el final fracasado de varios proyectos económicos, mientras que el Chaco se presenta como un territorio pujante que no sentiría la crisis económica hasta entrados los 60 .

Pero en las preocupaciones por la definición de una región geográfica, Miranda coincide nuevamente con Canal, para quien el hombre es, fundamentalmente, un "ser situado", que sólo puede realizarse en su dimensión esencialmente humana -la de la culturaa partir de una interrelación con el entorno geográfico que le sirve de contexto existencial. Desde esa perspectiva, había postulado la necesidad del regionalismo -entendido como "diálogo inmediato del espíritu con la realidad localizada de la naturaleza y de la historia, como exigencia para la "justificación" de la cultura ${ }^{26}$. De allí la preocupación central por definir el espacio geográfico regional que manifiesta la obra de Miranda, en cuanto este espacio permite dotar de sentido a la historia del Chaco y, por lo tanto, de una identidad a sus habitantes.

\section{Miranda y la definición regional}

Bernardo Canal Feijóo planteó por primera vez la necesidad de una planificación regional para la reconstrucción social y económica del Noroeste y tuvo una destacada actuación como organizador del Primer Congreso de Planificación Integral del Noroeste Argentino. Sostenía que "sólo mediante una planificación del Norte tomado como una unidad

${ }^{25}$ Ramón A. Leoni Pinto. Obra y pensamiento historiográfico de Bernardo Canal Feijóo. San Miguel de Tucumán, UNT, 1997.

${ }^{26}$ Leonor Arias Saravia de Perramon. "Bernardo Canal Feijóo: la "autenticación" de la cultura". En: Hugo Biagini. El pensamiento latinoamericano del siglo XX ante la condición humana. Versión digital, iniciada en junio de 2004, a cargo de José Luis Gómez-Martínez. URL: www.ensayistas.org/critica/generales/C-H/ argentina/canal-feijoo.htm 
de integración geográfica, económica y sociológica" podía encontrarse el camino para las soluciones de los problemas comunes ${ }^{27}$.

La regionalización que propugnaba Canal Feijóo se basaba en la trascendencia natural y racional de lo provincial -hecho meramente político "declarativo y nominal" que disocia una realidad unitiva en forma de "un rompecabezas de pequeñas ficciones contingentes y deficientes"-, pues "esos límites provinciales son más convencionales que reales". El universo de análisis es, por lo tanto, el Noroeste considerado como unidad histórico-cultural donde se despliega la vida de seis provincias que abarcan una cuarta parte del territorio nacional ${ }^{28}$.

Esta perspectiva sería adoptada por quienes plantearon la necesidad de definición de una región Nordeste, también vinculada en torno a problemas comunes, como lo señalara Hernán Gómez en la década de 1940. Pero la consideración de la región nordeste como una región subnacional aparece entonces con el carácter de región administrativa y funcional, antes que histórica -a diferencia de como se definía a la región chaqueña-, con un pasado breve, cuyas fronteras traspasan los límites de las regiones históricas ${ }^{29}$.

Se ha señalado que el Nordeste no sólo no constituye una región geográfica, sino que tampoco se identifica en ella a una única región histórica. Si se examina su pasado, se advierten procesos heterogéneos asentados en los distintos espacios que hoy lo componen. Las diversas concepciones en torno a la región condujeron a delinear límites variados y a buscar sus raíces históricas en diferentes momentos y circunstancias, muchas veces descuidando que estas unidades territoriales que son las regiones -como la Nordeste- han sido construidas por los modernos procesos políticos de regionalización ${ }^{30}$.

La denominación de Gran Chaco aplicada a un extenso territorio presentó desde sus orígenes dos características particulares: una generalizada homogeneidad en sus aspectos físicos y biológicos y una población aborigen que impidió asentamientos perdurables de los "blancos" hasta muy entrado el siglo XIX. La percepción de estas características fue alimentando las leyendas de misterio e inhabitabilidad que el territorio conservó hasta el siglo XX, al tiempo que reforzaba su consideración regional ${ }^{31}$. Ello se vio acentuado por la situación política: incorporado al estado argentino como territorio nacional en 1872 -aunque ocupado efectivamente por aquél a mediados de la década de 1880-, mantendría ese status hasta la década de 1950, cuando se iniciaron los procesos de provincialización.

Por su parte, la creación de la Universidad Nacional del Nordeste en 1957, que debía extender su influencia sobre Formosa, Misiones, Chaco y Corrientes, contribuyó a la definición

\footnotetext{
${ }^{27}$ Alicia Poderti. De Güemes a Perón. Revistas culturales y periodismo en Argentina, Buenos Aires, Nueva Generación, 2005.

${ }^{28}$ Ibid.

${ }^{29}$ Tomamos aquí la clasificación de Fure. Cit. por Einar Niemi., op, cit.

${ }^{30}$ Einar Niemi. "Region and Regionalisation. Backround, trends, theories and models". En: $19^{\circ}$ International Congress of Historical Sciences, Oslo, 2000.

${ }^{31}$ Héctor Rubén Borrini. La geografía humana y su desarrollo en la región centro-oriental del Chaco, Resistencia, IIGHI-CONICET, 1994, p. 41.
} 
de este ámbito regional. En los propósitos de sus organizadores quedaba establecida la inserción regional de la institución, que debía responder a los problemas y las necesidades que planteaba este espacio.

En la década de 1960 se produjo un proceso de regionalización desde el gobierno central, entendido como el deseo de planificación social, reforma económica y programas de desarrollo que requieren un nivel intermedio entre los niveles nacional y local. Específicamente, en 1.966, el gobierno de la denominada Revolución Argentina dictó la Ley 16.964, y su correspondiente reglamentación, que dividió al país en regiones como parte de un Consejo Nacional de Desarrollo (CONADE). Según el esquema CONADE, se establecía que la Región Nordeste estaba integrada por las provincias de Misiones, Corrientes, Formosa, Chaco y norte de Santa Fe.

Una revisión realizada a la organización de las estructuras administrativas, a los periódicos zonales, a las denominaciones de establecimientos e instituciones permite demostrar el arraigo que fue adquiriendo esta perspectiva ${ }^{32}$. Las reuniones de la Junta de Gobernadores de la región que se realizaron entonces tenían entre sus objetivos lograr "la consolidación de un potente polo dinámico en el área Corrientes-Resistencia".

Esta definición de la región nordeste fue debatida por quienes, basados en criterios geográficos e históricos, proponían hablar de una región chaqueña constituida por las actuales provincias del Chaco, Formosa, norte de Santa Fe, este de Salta y NE de Santiago del Estero, unidas por la continuidad geográfica y por comunes problemáticas económicas y de ocupación del espacio, como se manifestó en 1975, cuando el gobierno chaqueño organizó el " $1{ }^{\circ}$ Congreso Económico Regional del Chaco Gualamba". Aquí quedaba definida también una región subnacional, con un recorte espacial diferente a la región Nordeste.

En esta dificultad para definir el marco regional intervino también el tardío proceso de conformación de lo que Van Young denomina regionalismo (identificación consciente, cultural, política y sentimental que grandes grupos de personas desarrollan con el espacio regional). Dicha problemática se observa en la obra de Guido Miranda, quien adherirá sucesivamente -y a veces coetáneamente- a las dos concepciones arriba señaladas, aunque sus trabajos se concentraron fundamentalmente en la región chaqueña.

Al realizar, en 1952, la defensa del nombre Chaco para la provincia, advertía que "no significa una posición estrecha, localista, provinciana; sino un sentido amplio, transprovincial, regional, que no se empequeñece con los límites políticos de la Provincia, sino que se extiende con amplitud cultural a toda una región geográfica y se integra en el país"33. En El paisaje chaqueño (1954 y 1961) describe esta región y sostiene que "existe una notoria compenetración regional de nuestra provincia con el Gran Chaco, del cual está llamada a ser la cabecera económica".

La editorial que fundara entonces y que publicara sus primeros trabajos se denominó Norte Argentino, acepción que comprendía parte de las provincias de Santa Fe, Santiago

\footnotetext{
${ }^{32}$ Centro de Estudios Regionales del Nordeste Argentino. Sobre región y regionalismo. Corrientes, 1978, p.p. $10-11$.

33 Ibid., p. 45.
} 
del Estero y Salta, así como Chaco, Formosa, pero también Corrientes y Misiones, en un intento por fundir la región chaqueña con el nordeste.

En El paisaje...sostiene que la región chaqueña es una entidad que "se mostró de hecho, al primer contacto con los blancos, con resaltante individualidad panorámica", por lo que confirma el "destino regional del Chaco"34. Revela aquí lo que Gorelik denomina un “'modernismo tierra adentro': esa mezcla, entonces, de etnografía, historia regional y planificación regional”, influenciado por el pensamiento de Lewis Mumford ${ }^{35}$.

Más tarde, ya diseñado el esquema CONADE, realiza el esfuerzo por fundamentar históricamente esta regionalización en una serie de artículos titulados "Perfil del Nordeste" (1968/1969), publicados en el diario El Territorio. Se ha advertido que la región nordeste precisaba de una historia que la fundara y fundiera en rasgos específicos. Así surgiría una historiografía de construcción nordestina que "debió hilvanar los retazos de las historias de cada provincia para sustentar la existencia de una región Nordeste que resultaba ser bastante inédita y reciente" ${ }^{36}$. Miranda señala en dichos artículos que esta unidad regional es un enfoque contemporáneo a la creación de la UNNE y acepta que el Nordeste no presenta unidad geográfica, si bien la tiene en cuanto a la ocupación humana, homogeneizada por la cultura guaraní ${ }^{37}$. No significaba esto la recuperación de un legado indígena, sino el aporte manifiesto en el folklore, las leyendas y la música.

En este esfuerzo por definir el "perfil del Nordeste" no puede evitar mostrar imágenes fragmentadas para describir cada una de las realidades provinciales, sin lograr una visión de conjunto, como sí lo lograra al trabajar sobre la región chaqueña.

El dilema queda planteado, como se indica en el Prefacio de Fulgor del desierto verde, donde se pregunta "¿Gran Chaco o Nordeste argentino?"

\section{Imágenes identitarias del Chaco}

Miranda, al igual que Canal, sigue lo que Gorelik denomina el tercer camino de la vocación interior en la cultura argentina: el camino científico, de la indagación etnográfica, la valorización del folklore, la arqueología y la historia regional.

La búsqueda de los rasgos identitarios está presente en todos sus trabajos. En uno de ellos sostiene que los escritores chaqueños "tenemos la obligación de alumbrar esa ladera incógnita, donde no es cierto que estuviera agazapado el mundo del retraso, sino aquel donde a causa de la aplicación de un insuficiente concepto de progreso se secaron las fuentes naturales de una prístina cultura regional" 38 . Esta formulación, realizada a mediados de la década de 1960, ya lleva la impronta del diagnóstico desencantado de Canal.

En Tres ciclos chaqueños distingue tres etapas o ciclos en el desarrollo del Chaco: Fundación, Tanino y Algodón. Según Alfredo Veiravé, Miranda despliega "una realidad

\footnotetext{
${ }^{34}$ Delia T. Álvarez de Tomassone. Guido Miranda...op.cit., p.80.

${ }^{35}$ A. Gorelik, op.cit.; p. 24.

${ }^{36}$ Héctor Eduardo Jacquet. Haciendo Historia en la aldea. Misiones, 1996. Posadas, 2002; p.52

${ }^{37}$ Delia Teresita Alvarez de Tomassone. "Guido Miranda, testigo...; op.cit".

${ }^{38}$ G. Miranda Al norte del paralelo 28. Resistencia, Norte Argentino, 1966; p.15
} 
envolvente de ciclos y círculos para mostrar la conciencia de historicidad de un pueblo. Su obra general es una teoría de la cultura regional inserta en la universalidad americana y una continuidad de todas las búsquedas que forman la tradición del ser nacional. Una obra, además, que es la identidad del Chaco como epicentro (y no como periferia) de la constitución orgánica del país, al norte del paralelo $28^{\circ}{ }^{\circ 39}$. Señala Veiravé que la originalidad de Miranda consiste en invertir los términos de la historia de la Nación, vista ahora desde una aparente periferia que deja de ser dependiente en cuanto se convierte en centro diseminador de una nueva colonización. Advierte que, sin falsos localismos, fue ampliando el círculo de los contextos regionales para insertarse en la realidad nacional.

Probablemente aquí se marque también una diferencia con Canal, quien sostuvo la oposición nación-provincias como lucha entre narrativas periféricas y centrales, mientras que Miranda advierte un proceso de integración, en el cual el Chaco es clara realización de un proyecto nacional, aunque con una dinámica propia que no por ello significó un enfrentamiento.

Recurre a Canal y sus reflexiones en torno a la tensión Buenos Aires/interior para plantear luego la distinción entre las provincias preconstitucionales y las postconstitucionales. "Existe la voluntad explícita de asumir una identidad comprensiva del pluralismo cultural latente, con la secreta presencia de la función mediadora que las provincias post-constitucionales podrán desempeñar en beneficio de la integración nacional, entre los históricos polos de la Capital Federal y las provincias pre-constitucionales"40.

Aquí Resistencia cumple un papel central. Miranda toma el concepto de José Luis Romero de "ciudad burguesa" para tipificarla y señala que, a diferencia de las ciudades hidalgas y a semejanza de otras capitales de territorios nacionales, es la resultante de un proceso de desarrollo fomentado desde Buenos Aires sobre la tabla rasa del desierto, mediante la internación de inmigrantes europeos y la confluencia de transmigrantes criollos, por lo que revela escasa filiación con las etapas precedentes de la ciudad latinoamericana.

La obra, que cuenta con abundante documentación, transita por los caminos del ensayo, a fin de detectar los problemas planteados por el desarrollo socioeconómico del Chaco, así como sus posibles soluciones -tal como se lo propusiera Lestani-. La periodización brindada por Miranda no responde a la de la historia nacional sino a la de la propia historia chaqueña; abandona los acontecimientos políticos para concentrarse en las transformaciones socio-económicas que condujeron a la conformación de una identidad que buscará definir en sus obras posteriores, aunque sin llegar a desarrollar una reflexión sistemática, contentándose con brindar cuadros, apuntes e hilos interpretativos.

Entre ellos se destaca la definición de la “civilización de la selva”, conformada por la cultura precolombina guaraní, sumada a un proceso de aculturación común en toda la región, con la integración de las colectividades inmigrantes y los grupos argentinos provenientes de otras provincias. En este proceso ocupa un lugar medular el obraje, que "resultó la forja en

\footnotetext{
${ }^{39}$ Alfredo Veiravé, “Chaco en el territorio de la imaginación”. En: Universidad Nacional del Nordeste. Facultad de Humanidades. Testimonios. Resistencia, Universidad Nacional Del Nordeste, 1983, p.p. 552-553.

${ }^{40}$ G. Miranda. La rosa étnica del Chaco. En: Edgardo Rossi. La identidad del Chaco.
} 
que se amalgamaron distintas naciones aborígenes y otros tantos mestizajes provinciales" y engendró "el embrión de una sociedad singular en la entraña del Chaco"41.

Miranda manifiesta interés por el folklore que surgió de esta aculturación en el obraje, proceso que denominó de "folklorización", aunque no teorizó sobre el mismo, valiéndose otra vez aquí de las reflexiones de Canal. Si bien reconoce la impronta de la vertiente santiagueña en el occidente chaqueño, resalta el extendido aporte guaraní en la lengua, la religiosidad popular y la música ${ }^{42}$.

La representación del Chaco como imagen fragmentada que atraviesa su obra se entrecruza con la del "crisol de razas", para terminar por aseverar que su característica distintiva es precisamente el cambio, la absorción y acrisolamiento de las distintas vertientes culturales, como lo indican ya los títulos de dos de sus trabajos: El rostro cambiante del Chaco y La rosa étnica del Chaco.

Toma la visión de Canal sobre el bosque santiagueño para afirmar que "comprendemos ahora, que un paisaje intuible por la sensibilidad recatada en circunstancias entrañables, al que sólo se accede mediante estrecha compenetración, abrazará con fuerza al habitante" ${ }^{43}$ y luego advertir que "Arrasarlo será desgarrar sutiles raíces anímicas". Considera que las reflexiones de Canal "cobran así merecida perennidad, porque constituyen una clave sociológica sin par para comprender la múltiple repercusión de los estragos provocados por su explotación irracional". La preocupación por la preservación del paisaje que dio origen y le da sustento a una determinada cultura será común a ambos, así como la propuesta de organización racional de los recursos naturales, en la que se destaca la importancia dada a la conectividad interprovincial de los ríos; en el caso de Miranda, la canalización del río Bermejo.

\section{Reflexiones finales}

Si bien el ensayo nacional de mediados de siglo XX y especialmente la obra de Canal Feijóo, marcan la producción de Guido Miranda, éste no adhiere a la visión desencantada con respecto a los procesos de modernización del país ni a la oposición centro/ periferia, sino que reconoce un proceso de integración de la región en la nación a través de la ocupación del "desierto" y de la llegada de la inmigración, proceso cuyos conflictos no son centrales y que adquiere una dinámica propia, producto de las peculiaridades del medio geográfico.

Su definición de la región no es clara y presenta variantes entre un Chaco que aparece en sus ensayos con espesura histórica y raíz geográfica y un Nordeste que buscará fundamentar con vistas a la planificación para el desarrollo regional. La región se presenta entonces como una realidad por construir, tal como lo planteara en la década de 1930

\footnotetext{
${ }^{41}$ G. Miranda. Al norte...; op. cit..

${ }^{42}$ G. Miranda. Fulgor...; op. cit.; p.p. 64-65 y "El folklore guaraní forma un factor fundamental de la regionalización". En: El Territorio, Resistencia, 3-XII-1968.

${ }^{43}$ Ibid., p.14
} 
Lewis Mumford, al afirmar que la región no se encuentra como un producto acabado en la naturaleza, ni es solamente una creación humana, sino una obra de arte colectiva ${ }^{44}$, o como lo expresara Miranda, "una entidad viva, capaz de transformaciones incesantes", concepción que pareciera haberse impuesto en quienes pensaron el Chaco.

\title{
Resumen
}

La cuestión de la definición regional de lo que hoy se denomina Nordeste argentino ha estado sometida a miradas contrapuestas. En esta oportunidad analizamos las propuestas de un autor cuya obra ha sido central en la historiografía chaqueña y que sólo recientemente ha merecido estudio. Guido Miranda (1912-1994), maestro y periodista incorporado a las filas del socialismo, es autor de una obra considerada un clásico: Tres ciclos chaqueños (Crónica histórica regional) (1955); a través de su producción escrita, buscó desentrañar la identidad regional.

Nos proponemos interrogar al ensayo de Miranda más que como clave de interpretación, como fuente compleja de representaciones de la región, partiendo de la hipótesis de que cumple un papel fundamental en su construcción la recepción de la obra de Bernardo Canal Feijóo, con quien Miranda establece un continuo diálogo para su elaboración de una propuesta de historia regional.

$$
<\text { Historiografía }><\text { Región }><\text { Chaco }><\text { Nordeste }><\text { Guido Miranda }>
$$

\begin{abstract}
The issue of the regional definition of what today is named Argentina Northeast has been submitted to opposite looks. In this opportunity we analyze the propositions of an author whose work has been central in Chaco historiography: Guido Miranda (1912-1994). Teacher and journalist incorporated into the rows of the socialism, has recently deserved several studies. He is the author of Tres ciclos chaqueños (Crónica histórica regional) (1955), considered a "classic" in the regional literature, and his whole production has been related to de study of the regional identity.

At this time, we propose to interrogate Miranda's essay as a complex source of representations about the region. Our hypothesis is that the influence of Bernardo Canal Feijóo, through his written production and the continuous dialogues between them, has been a significant influence on the Miranda's proposition of regional History
\end{abstract}

$<$ Historiography $><$ Region $><$ Chaco $><$ Argentina Northeas $><$ Guido Miranda $>$

${ }^{44}$ Cit. por John Friedmann y C. Weaver. Territory and Function. The Evolution of Regional Planning, 1979:31, E. Arnold, London. 
